\title{
Haematological features of primary myelodysplastic syndromes (PMDS) at initial presentation: a study of
}

\section{8 cases}

\author{
SURENDER K JUNEJA, MICHĖLE IMBERT, HÉLÈNE JOUAULT, \\ JEAN-YVES SCOAZEC, FRANÇOIS SIGAUX, CLAUDE SULTAN \\ From the Central Service of Haematology-Immunology, Henri Mondor Hospital, 94010 Créteil, France
}

SUMMARY The haematological features of 118 cases of primary myelodysplastic syndromes (PMDS) were reviewed to see how these could be related and classified according to the recent FAB proposals. A majority of the cases were elderly who presented with a macrocytic or normocytic anaemia and reticulocytopenia. Cases of acquired idiopathic sideroblastic anaemia (AISA) usually had normal leucocyte and platelet counts, erythroid hyperplasia, marked dyserythropoiesis and more than $20 \%$ ringed sideroblasts. Cases of refractory anaemia with excess of blasts (RAEB) had frequent neutropenia and thrombopenia usually with prominent dysgranulopoiesis and dysthrombopoiesis. Refractory anaemia or refractory cytopenia appeared morphologically to be a heterogeneous group. Leukaemic transformation did not occur in any of these 16 cases of AISA whereas six of the 34 cases of RAEB transformed into acute leukaemia. It appears that the cases of PMDS present with well defined haematological features which permit recognition of different groups; these latter groups appear to be morphologically and prognostically distinct.

A group of primary haematological disorders which may precede or predispose to the development of acute leukaemia, have been described in the past under different names including refractory anaemia with or without sideroblasts, ${ }^{12}$ refractory anaemia with excess of blasts, ${ }^{3}$ smoldering acute leukaemia ${ }^{4}{ }^{\text {preleukaemia }},{ }^{5}$ preleukaemic states $^{6}$ and preleukaemic syndrome. ${ }^{7}$ These are now grouped under the term myelodysplastic syndromes (MDS). A variable incidence of leukaemic transformation and prognosis, have been reported among each of the various subgroups $s^{9-13}$ - for example, the incidence of leukaemic transformation in acquired idiopathic sideroblastic anaemia (AISA) has been reported to vary from 7 to $25 \% .^{9-11}$ Since these disorders have a wide range of morphological features, the variable prognosis reported, may be related to differences, in part to the diagnostic criteria employed for defining and subgrouping the various MDS. The recent proposals ${ }^{14}$ is have been a lead in this direction. These proposals need to be substantiated by studies including a large number of cases.

Accepted for publication 14 June 1983
This report presents the results of such a large series consisting of 118 cases to see how these cases could be related and classified according to the above proposals.

\section{Patients and methods}

Data relevant to 118 cases diagnosed as having MDS on the basis of morphological features and having up to $20 \%$ blasts in the bone marrow were reviewed. Cases of MDS having between 20 and $30 \%$ marrow blasts or Auer rods or $5 \%$ or more circulating blasts (classified as RAEB in transformation according to 1982 FAB proposals) have been included in another study ${ }^{16}$ consisting of these cases along with borderline cases of AML, in an attempt to determine distinguishing features of these two groups. During the same period, 20 cases of MDS, secondary to chemotherapy or radiotherapy or both and 12 cases with associated myelofibrosis were also seen. The haematological and clinical features including prognosis of a majority of these cases have been published previously ${ }^{17} 18$ and therefore these were not included in this study. Another 10 cases of MDS in which the poor bone marrow cellularity on 
aspirate could not be confirmed by bone biopsy were excluded from the present study. In the latter cases the bone marrow aspirate specimen was considered to be inadequate for judging the cellularity and the morphological features. Cases having dysmyelopoiesis secondary to vitamin $B_{12}$ or folic acid deficiency were not considered for the present study. The slides on all cases were reviewed by three observers (SKJ, CS \& MI) and there was agreement in the majority of cases. In cases with disagreement the slides were reviewed and a consensus diagnosis was considered. The blast cells were divided into agranular and granular blasts respectively type I and II, according to the FAB classification (1982). Routine haematological examinations were performed according to standard methods. ${ }^{19} 20$ The ringed sideroblasts were defined as erythroblasts containing five or more Prussian-blue positive granules covering one-third or more of the circumference of the nucleus. ${ }^{21}$ The percentage of ringed sideroblasts was calculated from a minimum of 100 erythroblasts counted. The percentage of blast cells and various other myeloid cells was calculated after counting at least 300 marrow cells; the count was repeated in some cases. The haematological data on all the cases was entered in a microcomputer (Commodore computer 8032) for analysis. All the cases included in the present study could be classified into one of the groups of the recent FAB proposals. ${ }^{14}$ Thus there were 43 cases of AISA or refractory anaemia with ringed sideroblasts, 66 cases of RAEB, nine cases of refractory anaemia (RA) or refractory cytopenia (RC). The nine cases of RAEB having monocytosis $(>1000 / \mu \mathrm{l})$ were not excluded from this category. The morphological abnormalities of the haematopoietic cells were recognised as already described. ${ }^{8}$ Marked dyserythropoiesis was defined as the presence of two or more of the following morphological abnormalities in the majority $(>50 \%)$ of the erythroblasts: gigantism, multinuclearity, asynchrony of maturation between the nucleus and cytoplasm, cytoplasmic vacuolation, karyorrhexis, nuclear budding, basophilic stippling, Howell-Jolly bodies and megaloblastic changes.

Marked dysgranulopoiesis was defined by the presence of prominent degranulation of the majority of the granulocytes or the presence of two or more of the following morphological abnormalities in the majority of the granulocytes: degranulation, abnormal granules, pseudo Pelger anomaly, abnormal promyelocytes or dystrophic blasts. Dysthrombopoiesis was considered to be marked when majority of the megakaryocytes were morphologically abnormal (micromegakaryocytes, megakaryocytes with fragmented nucleus, dystrophic megakaryo- cytes). Statistical analysis was performed by means of the $\chi^{2}$ test.

\section{Results}

\section{AGE AND SEX}

The age and sex distribution of the cases is shown in the Figure. The age range of the patients at the initial presentation was 48-95 yr with all but two of them being more than $50 \mathrm{yr}$ old. Ninety percent of all the cases were older than $60 \mathrm{yr}$. The median age for the groups AISA and RAEB was 75 and $73 \mathrm{yr}$ respectively. There were 58 men and 60 women.

\section{CLINICAL FEATURES}

Symptoms related to anaemia or a routine examination led to the discovery of the disease in most of the cases. Haemorrhagic symptoms occurred in seven cases and infection preceded the discovery in 10 cases. Significant organomegaly was not seen in any case.

\section{PERIPHERAL BLOOD AND BONE MARROW FINDINGS}

The principal peripheral blood and bone marrow findings of AISA and RAEB are shown in Tables 1, 2 and 3 . Compared to AISA, significantly more cases of RAEB had $\mathrm{Hb}<8 \mathrm{~g} / \mathrm{dl}(\mathrm{p}<0.02)$, neutropenia $<1.5 \times 10^{9} / 1(p<0.001)$, thrombopenia $<150 \times 10^{9} / 1(\mathrm{p}<0.001)$, marked dysgranulopoiesis and marked dysthrombopoiesis and increased number of promyelocytes. On the other hand, significantly more cases of AISA had macrocytosis $>100 \mathrm{fl}(\mathrm{p}<0.001)$, erythroid hyperplasia and marked dyserythropoiesis. No significant difference was found between the two groups in the degree of reticulocytopenia $\left(<40 \times 10^{9} / 1\right)$ or leukopenia $\left(<4 \times 10^{\circ} / 1\right)$. The mean marrow blast count in cases of AISA was $2 \%(2.37 \pm 1.09)$ whereas for the cases of RAEB, it was $10 \%$ $(9 \cdot 69 \pm 3 \cdot 20)$. Among the cases of RAEB, 17 $(26 \%)$ had pancytopenia, $30(45 \%)$ had bicytopenia (18 anaemia + thrombopenia, 11 anaemia + neutropenia, 1 neutropenia + thrombopenia), and 19 $(29 \%)$ had isolated cytopenia (18 anaemia and 1 thrombopenia). In the bone marrow, morphological evidence of mild dysgranulopoiesis in seven cases and mild dysthrombopoiesis in five cases, were observed in AISA. Morphological abnormalities of the polymorphonuclear cells in the peripheral blood were not observed in the group AISA. On the other hand, 17 cases of RAEB had abnormalities of polymorphonuclear cells, in the form of degranulated polymorphonuclear cells alone (7 cases) or with associated Pelger-like anomaly (9 cases); one case had abnormally large granules in the polymor- 


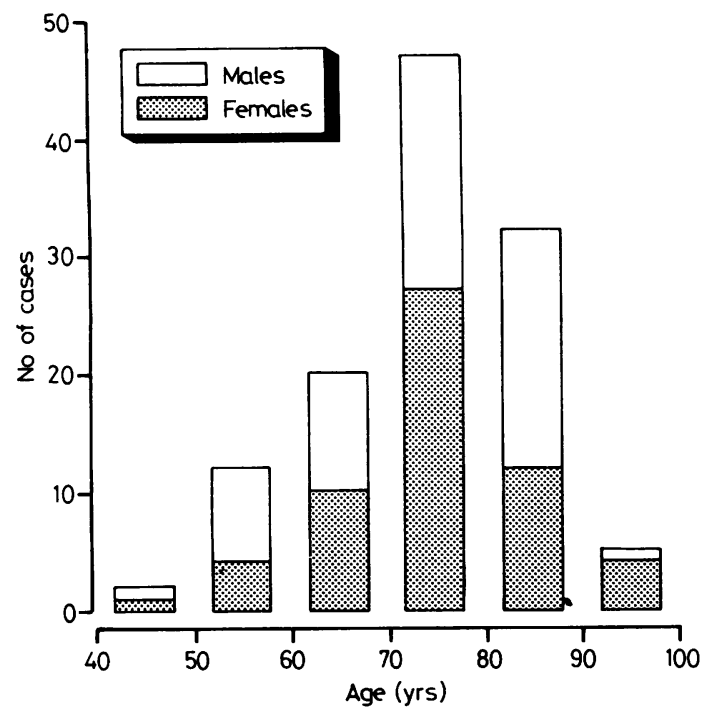

Age and sex distribution of the 118 cases of primary myelodysplastic syndromes.

Table 1 Principal peripheral blood findings in cases of AISA

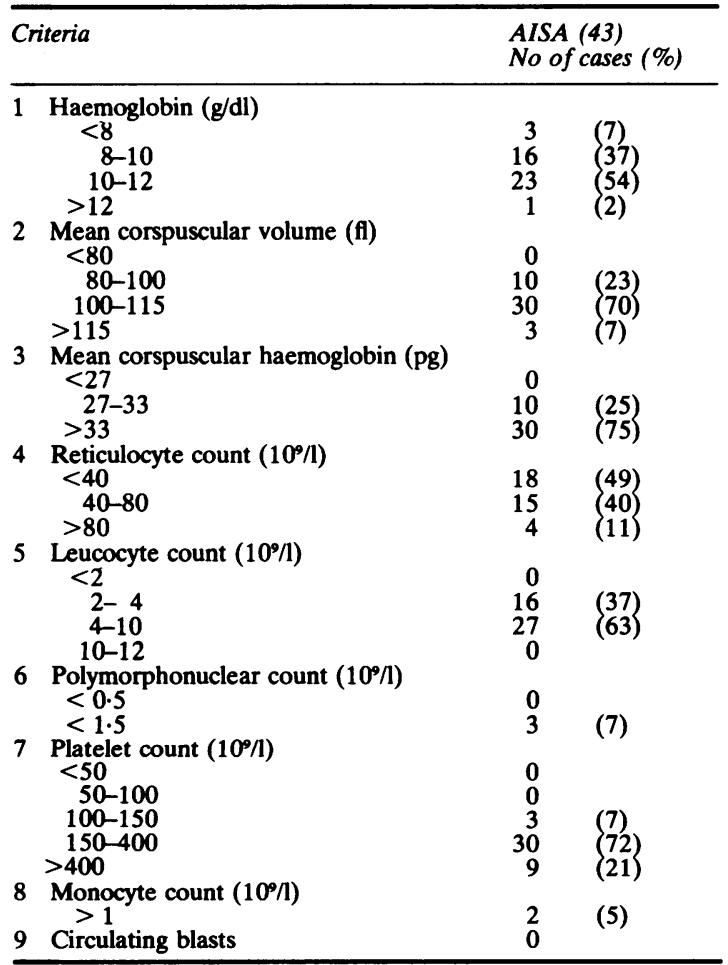

AISA $=$ acquired idiopathic sideroblastic anaemia.
Table 2 Principal peripheral blood findings in cases of $R A E B$

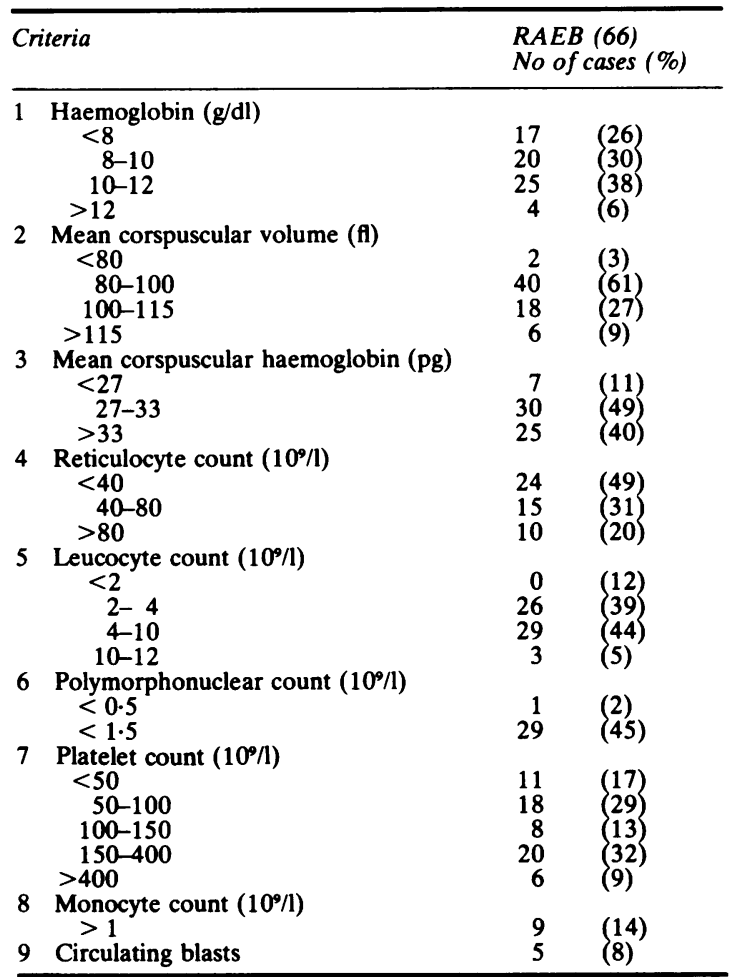

RAEB = refractory anaemia with excess of blasts.

phonuclear cells. Circulating giant platelets were seen in eight cases of AISA and in 20 cases of RAEB. Hypochromia, target cells, schistocytes, tear drop cells, basophilic stippling and circulating erythroblasts were seen in a small number of cases of both groups.

Since the majority of cases of AISA had a long median duration of survival and needed little if any supportive therapy apart from occasional blood transfusions, it was difficult to have a follow-up for all these cases. However, follow-up varying from 6 months to 64 months was available in 15 cases and for one case up to $13 \mathrm{yr}$. Ten of these had a followup of 24 months or more. Acute leukaemia did not develop in any of these cases. However, acute myelofibrosis developed as a terminal event after 13 years in one of these. One patient, a known diabetic died of septicaemia after 24 months follow-up. Follow-up varying from 2 to 60 months was available in 34 cases of RAEB. Among these, 15 cases were followed for more than 1 year and 10 cases for more than 2 years. Twenty of the cases followed, died after a period varying from 2 months to 45 months. One patient died of pulmonary embolism 
Table 3 Principal bone marrow findings in the cases of $A I S A$ and $R A E B$

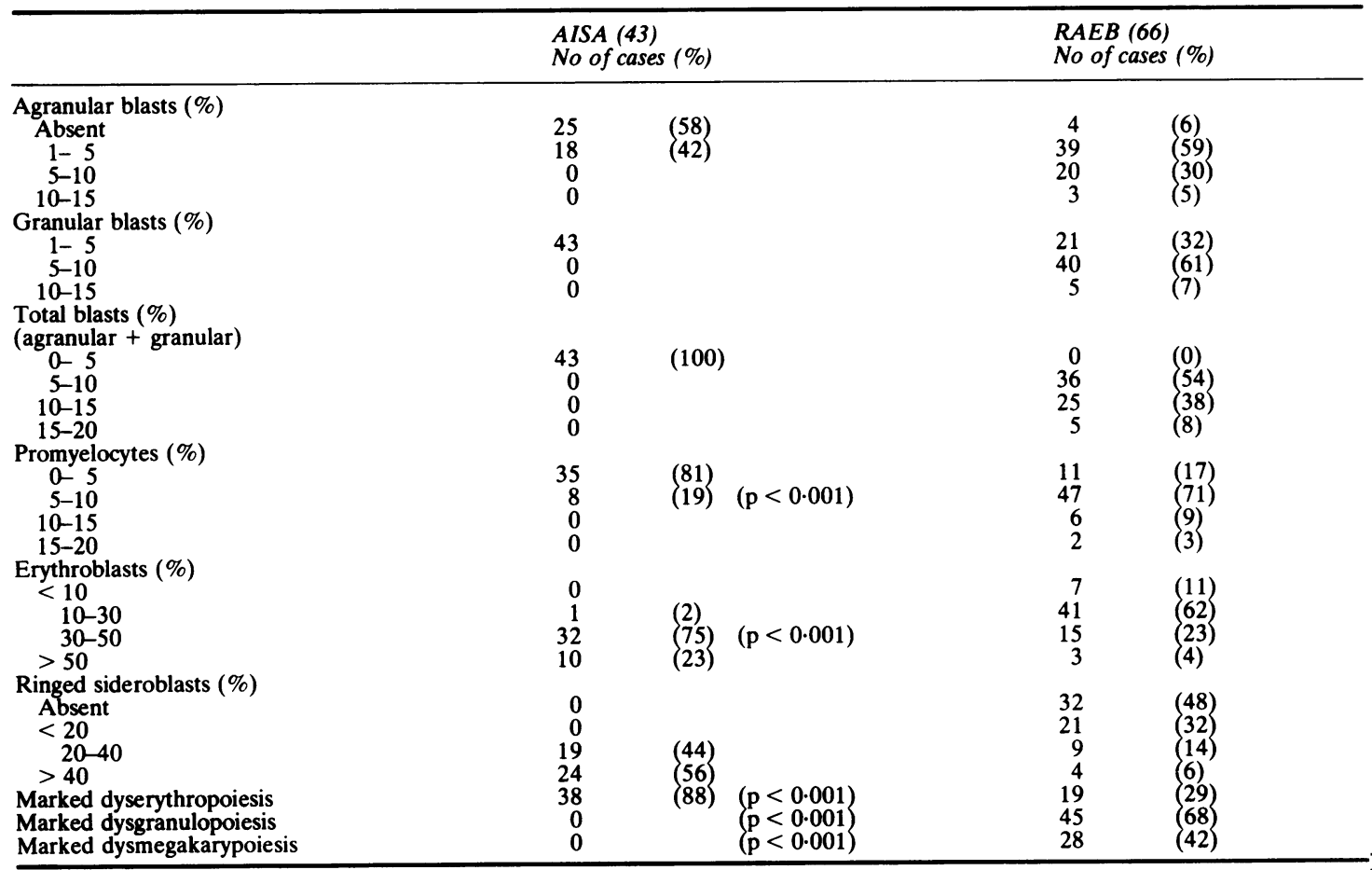

AISA = acquired idiopathic sideroblastic anaemia.

RAEB = refractory anaemia with excess of blasts.

Table 4 Haematological features at initial presentation of the six cases of RAEB which transformed into acute leukaemia

\begin{tabular}{|c|c|c|c|c|c|c|c|c|c|c|c|c|}
\hline & \multirow{2}{*}{$\begin{array}{l}H b \\
(g / d l)\end{array}$} & \multirow{2}{*}{$\begin{array}{l}P M N \\
\left(\times 10^{9} / l\right)\end{array}$} & \multirow{2}{*}{$\begin{array}{l}\text { Platelets } \\
\left(\times 10^{\circ} / l\right)\end{array}$} & \multirow{2}{*}{$\begin{array}{l}C B \\
(\%)\end{array}$} & \multicolumn{2}{|c|}{ Marrow blasts } & \multirow{2}{*}{$\begin{array}{l}\text { Erythro- } \\
\text { blasts (\%) }\end{array}$} & \multirow{2}{*}{$\begin{array}{l}R S \\
(\%)\end{array}$} & \multicolumn{3}{|c|}{ Morphological evidence of } & \multirow{2}{*}{$\begin{array}{l}\text { Time from diagnosi } \\
\text { to leukaemic } \\
\text { transformation } \\
\text { (months) }\end{array}$} \\
\hline & & & & & Agranular & Granular & & & $\begin{array}{l}\text { Dyserythro- } \\
\text { poiesis }\end{array}$ & $\begin{array}{l}\text { Dysgranu- } \\
\text { lopoiesis }\end{array}$ & $\begin{array}{l}\text { Dysthrom- } \\
\text { bopoiesis }\end{array}$ & \\
\hline $\begin{array}{l}1 \\
2 \\
3 \\
4 \\
5 \\
6\end{array}$ & $\begin{array}{r}11 \cdot 4 \\
8 \cdot 1 \\
9 \cdot 4 \\
6 \cdot 8 \\
8 \cdot 2 \\
9 \cdot 1\end{array}$ & $\begin{array}{r}7590 \\
884 \\
858 \\
2130 \\
1426 \\
2016\end{array}$ & $\begin{array}{r}79 \\
44 \\
27 \\
513 \\
355 \\
31\end{array}$ & $\begin{array}{l}0 \\
1 \\
0 \\
0 \\
0 \\
0\end{array}$ & $\begin{array}{l}2 \\
4 \\
4 \\
9 \\
5 \\
4\end{array}$ & $\begin{array}{l}4 \\
7 \\
8 \\
5 \\
4 \\
2\end{array}$ & $\begin{array}{l}30 \\
33 \\
44 \\
11 \\
32 \\
60\end{array}$ & $\begin{array}{r}13 \\
28 \\
2 \\
0 \\
33 \\
41\end{array}$ & $\begin{array}{r}++ \\
++ \\
+ \\
+ \\
+ \\
+ \\
+\end{array}$ & $\begin{array}{l}++ \\
++ \\
++ \\
++ \\
+ \\
++\end{array}$ & $\begin{array}{l}++ \\
++ \\
++ \\
++ \\
++ \\
++\end{array}$ & $\begin{array}{r}45 \\
3 \\
23 \\
40 \\
14 \\
10\end{array}$ \\
\hline
\end{tabular}

within 10 days of diagnosis. Death occurred as a result of infection (6 cases) and haemorrhage (3 cases). One patient died of cerebrovascular accident and in three cases the cause of death could not be ascertained. Leukaemic transformation with consequent death occurred in six cases (18\%). Initial haematological features of these latter six cases are shown in Table 4.

Seven of the nine cases which were classified as refractory anaemia or refractory cytopenia were anaemic; one of these two had isolated neutropenia and the other had neutropenia and thrombopenia.
The anaemia was macrocytic in seven cases and normocytic in two. This was associated with reticulocytopenia in six cases. Leukopenia was observed in four cases of which three had neutropenia. The polymorphonuclear cells were hypogranular in two cases. Thrombopenia was observed in five cases and it was marked $\left(<50 \times 10^{9} / 1\right)$ in four cases; giant platelets were noted in the peripheral smear in one case. Rare circulating blasts and erythroblasts were present in one case each. Eight of the nine cases had erythroid hyperplasia. Ringed sideroblasts varying from 3-13\% were seen 
in five of these and the Prussian-blue staining was negative in four cases. Dyserythropoiesis was a constant feature and was marked in two cases. Dysgranulopoiesis was variable being absent in three cases and marked in one case. Dysthrombopoiesis was present in six cases and absent in three. Leukaemic transformation occurred in two of these cases, 26 and 51 months respectively after the diagnosis.

\section{Discussion}

Myelodysplastic syndromes are characterised by anaemia, leukopenia or thrombocytopenia, as an isolated cytopenia or some combination thereof in the peripheral blood. The bone marrow in these cases is cellular and shows maturation defect in one or more of the cell lines. Death occurs in cases as a result of severe bone marrow insufficiency associated with or without development of acute leukaemia, or due to unrelated causes, since these disorders affect the elderly population.

The exact incidence of these disorders is unknown; however they do not seem to be infrequent. In our institution, in three years (1980-82) 126 new cases of AML were reported as compared to 65 new cases of PMDS. The majority of cases $(71 \%)$ are above the age of $70 \mathrm{yr}$ with a median age of $73 \mathrm{yr}$ emphasising that these syndromes occur in a relatively elderly population.

In the present study, the majority of the cases of AISA presented with fairly uniform haematological features characterised by a macrocytic or sometimes normocytic anaemia, reticulocytopenia, normal leucocyte and platelet count, erythroid hyperplasia, marked dyserythropoiesis and more than $20 \%$ ringed sideroblasts. The exact cause for this frequent macrocytosis observed is unknown. It may be related to the accelerated production of the erythroid cells and thus a shortened maturation time; ${ }^{22}$ it may also be due to alteration in the metabolism of RNA and DNA. ${ }^{23}{ }^{24}$ The defect in DNA synthesis in AISA, however, is not in the thymidylate synthesis, as in vitamin $B_{12}$ and folic acid deficiency..$^{25}$ Thrombocytosis $\left(>400 \times 10^{9} / 1\right)$ was observed in nine cases and only two of these had more than $500 \times 10^{9} / 1$ platelets. A higher percentage of cases of AISA with platelet count $>500 \times 10^{9} / 1$ has been reported in two earlier studies. ${ }^{96}$ Moreover, unlike the lower mean age reported ${ }^{26}$ for such cases having thrombocytosis, the mean age of the nine cases having $>400 \times 10^{9} / 1$ or two cases having $>500 \times 10^{9} / 1$ platelets in the present series was not significantly different from that of the whole group. A mild $\left(115-140 \times 10^{9} / 1\right)$ thrombopenia was observed in three $(7 \%)$ cases. A similar $(11.8 \%)$ or a slightly higher $(21 \%)$ incidence has been reported in two previous studies. ${ }^{96}$ In AISA thrombocytopenia has been reported to be a factor of poor prognostic value $^{1026}$ whereas thrombocytosis has been regarded as a favourable prognostic factor. ${ }^{1026}$

Though about one-third cases of AISA were leukopenic $\left(<4 \times 10^{9} / 1\right)$, neutropenia was infrequent $(7 \%)$. A much higher incidence $(48 \%)$ of neutropenia has been reported in one large series. ${ }^{9}$ The occurrence of qualitative and quantitative abnormalities of the granulocytes and platelets in a few cases of AISA (a disorder with predominant erythroid involvement in the majority of the cases) may be explained by the assumption that it is a haematopoietic stem cell disorder; the latter has also been demonstrated by the G6PD isoenzyme studies in a case of AISA. ${ }^{27}$ A variable incidence (7-25\%) of leukaemic transformation of AISA has been reported..$^{9-11}$ In a large series encompassing a review of the literature, this incidence was found to be $10 \% .^{10}$ In the present study, none of the 16 cases followed for a median duration of 24 months developed acute leukaemia. This absence of leukaemic transformation may be due to the small number of cases. It may also be related to the shorter median duration of follow-up since the median duration from the diagnosis of AISA to the onset of leukaemic transformation has been reported to be four years. 9 An additional factor may be the exclusion of cases with $5 \%$ or more marrow blasts irrespective of the percentage of ringed sideroblasts. The occurrence of acute myelofibrosis as a terminal event in AISA has also been reported. ${ }^{28} 29$

Cases of RAEB on the other hand were characterised by frequent neutropenia and thrombopenia with usually prominent morphological abnormalities of these cell lines. Circulating blasts were uncommon but were seen in five cases. Of the nine cases of RAEB with monocytosis $\left(>1 \times 10^{9} / 1\right)$ only one had monocyte count $>2 \times 10^{9} / 1$. These cases of RAEB having monocytosis without associated leukocytosis were not termed chronic myelomonocytic leukaemia; the latter term seems more appropriate for the atypical myeloproliferative disorder affecting the elderly population and characterised by a marked leukocytosis with monocytosis, frequent splenomegaly and skin infiltration and markedly increased serum and urinary lysozyme activities (Daniel MT, Flandrin G, unpublished data). A great majority $(83 \%)$ of the cases of RAEB were associated with an increased number of promyelocytes. This may constitute an additional diagnostic criterion especially when the promyelocytes show morphological abnormalities like numerous coarse or coalescent granules and several prominent nucleoli. ${ }^{3}$ Frequent neutropenia and thrombopenia as 
observed in the present study, are also factors indicating poor prognosis. ${ }^{30}$ Though only six (18\%) of the 34 cases of RAEB transformed into acute leukaemia ( $>30 \%$ marrow blasts), another two cases evolved into what would be termed RAEB in transformation: one of the latter two cases died at this stage and the other one is being followed regularly. In addition, the blast count increased to 13 to $17 \%$ in another three cases after a period of 4-60 months. In a recent series, ${ }^{13}$ using the same diagnostic criteria, the incidence of leukaemic transformation in RAEB was reported to be $44 \%$. In the same series the median survival was found to be slightly longer (14 months) compared to the present series (11 months). However, it is impossible to exclude the recruitment bias of cases of RAEB in the present series. It may be noted that among the six cases in the category of RAEB which transformed to acute leukaemia, three had ringed sideroblasts varying from 28 to $41 \%$. Classification of these cases as AISA would result in a different impression about the prognosis of this group. The prognostic significance of marrow blasts relative to the ringed sideroblasts has also been emphasised in another study $^{31}$ in which the marrow blast count was found to be the most highly correlated variable with prognosis in MDS. Another 10 cases with $5 \%$ or more marrow blasts had more than $20 \%$ ringed sideroblasts. These were, however, classified as RAEB not only because of an excess of marrow blasts but also because of the prominent dysgranulopoiesis and dysthrombopoiesis.

The cases of RA or RC were characterised by a macrocytic anaemia with associated reticulocytopenia. Neutropenia and thrombopenia were frequently associated. The marrow was cellular and showed varying degrees of dysmyelopoiesis affecting one or more cell lines. Erythroid hyperplasia was seen in almost all cases. Adding to this variable picture was the absence or the low percentage of the ringed sideroblasts (3-13\%). From the small number of cases in this group, it appears to be a heterogeneous group that needs to be better characterised by series consisting of a large number of cases.

It is apparent that the cases of PMDS present with well defined haematological features which permit recognition of different groups. The recognition of these features and a uniform classification may help avoid the prevailing confusion regarding the nomenclature and prognosis of various groups.

The authors thank Professor H Rochant, Head, Department of Clinical Haematology, for allowing us to study some of the patients. We are indebted to Mrs F Magny for typing the manuscript.
References

' Dacie JV, Smith MD, White JC, Mollin DL. Refractory normoblastic anaemia: A clinical and haematological study of seven cases. Br J Haematol 1959;5:56-82.

${ }^{2}$ Björkman SE. Chronic refractory anemia with sideroblastic bone marrow: a study of 4 cases. Blood 1956; II:250-8.

${ }^{3}$ Dreyfus B, Rochant H, Sultan C, et al. Anomalies of the blood group antigens and erythrocyte enzymes in 2 types of chronic refractory anaemia. Br J Haematol 1969;16:303-9.

${ }^{4}$ Rheingold JJ, Kaufman R, Adelson E, Lear A. Smoldering acute leukemia. N Engl J Med 1963;268:812-5.

${ }^{s}$ Block M, Jacobson LO. Preleukemic acute human leukemia. JAMA 1953;152:1018-28.

6 Pierre RV. Preleukemic states. Semin Hematol 1974;11:73-92.

' Linman JM, Bagby GC. The preleukemic syndrome: clinical and laboratory features, natural course and management. Blood Cells 1976;2:11-31.

Sultan C. Dysmyelopoietic syndromes, pp 749-752. In: Gralnick HR, (moderator): Classification of acute leukemia. Ann Intern Med 1977;87:740-53.

' Kushner JP, Lee GR, Wintrobe MM. Idiopathic refractory sideroblastic anemia. Clinical and laboratory investigations of 17 patients and review of the literature. Medicine 1971;50:139-59.

${ }^{10}$ Cheng DS, Kushner JP, Wintrobe MM. Idiopathic refractory sideroblastic anemia: incidence and risk factors for leukemic transformation. Cancer 1979;44:724-31.

"Lewy RI, Kansu E, Gabuzda T: Leukemia in patients with acquired idiopathic sideroblastic anemia: an evaluation of prognostic indicators. Am J Hematol 1979;6:323-31.

${ }^{12}$ Dreyfus B. Preleukemic states. Blood Cells 1976;2:33-45.

${ }^{13}$ Varela BL Chuang C, Bennett JM. Clinical significance of the new proposals for the classification of the myelodysplastic syn dromes (abstract). Blood 1982;60(Suppl):140.

${ }^{14}$ Bennett JM, Catovsky D, Daniel MT, et al. Proposals for the classification of the myelodysplastic syndromes. $\mathrm{Br} \mathrm{J} \mathrm{Haemata}$ 1982;51:189-99.

is Pierre R, Sultan C, Vardiman J. The myelodysplastic syndromes. Hematology transfusion. In: McArthur JR, ed. The education program of American Society of Hematology 1982:1.

${ }^{16}$ Imbert M, Scoazec JY, Croft M, et al. Myelodysplastic syndrome or acute myeloid leukemia? A study of 35 cases presenting with borderline features. Blood 1983;62 (suppl).

17 Dohy H, Genot JY, Imbert M, Ricard d'Agay MF, Sultan C. Myelodysplasia and leukaemia related to chemotherapy and/ or radiotherapy - a haematological study of 13 cases. Value of macrocytosis as an early sign of bone marrow injury. Clin Lab Haematol 1980;2:111-9.

${ }^{18}$ Sultan C, Sigaux F, Imbert M, Reyes F. Acute myelodysplasia with myelofibrosis: a report of 8 cases. $\mathrm{Br} \mathrm{J}$ Haematol 1981;49:11-6.

19 Dacie JV, Lewis SM. Practical haematology 5th ed. Edinburgh: Churchill-Livingstone, 1975.

${ }^{20}$ Sultan C, Priolet G, Beuzard Y, Rosa R, Josso F. Techniques en Hématologie. 2nd ed. Paris: Flammarion MédécineSciences, 1978.

${ }^{21}$ Bowman WD. Abnormal ("ringed") sideroblasts in various hematologic and non-hematological disorders. Blood 1961;18:662-71.

22 Bottomley SS. Sideroblastic anaemia. Clin Haematol 1982;11:389-409.

${ }^{23}$ Laurenco G, Embury S, Schrier SL, Kedes LH. Decreased ribosomal RNA content and in vitro RNA synthesis in purified bone marrow erythroblasts of patients with idiopathic ineffective erythropoiesis and Di Guglielmo disease. Am J Hematol 1978;5:169-82.

${ }^{24}$ Wickramasinghe SN, Hughes M. Capacity of ringed sideroblasts to synthesize nucleic acids and protein in patients with primary acquired sideroblastic anaemia. Br J Haematol 1978;38:34552. 
${ }^{25}$ Hoffbrand AV. Sideroblastic anemia in dyserythropoiesis. In: Lewis SM, Verwilghen RL, eds. London: Academic Press, 1977:139-49.

${ }^{26}$ Streeter RG, Presant CA, Reinhard E. Prognostic significance of thrombocytosis in idiopathic sideroblastic anemia. Blood 1977;50:427-32.

${ }^{27}$ Prchal JT, Throckmorton DW, Carroll AJ, Frison EW, Game RA, Prchal JF. A common progenitor for human myeloid and lymphoid cells. Nature 1978;274:590-1.

${ }^{28}$ Yeung KY, Trowbridge AA. Idiopathic acquired sideroblastic anemia terminating in acute myelofibrosis. Cancer 1977;39:359-65.
${ }^{29}$ Butler WM, Taylor G, Vishwanathan U. Idiopathic acquired sideroblastic anemia terminating in acute myelosclerosis. Cancer 1982;49:2497-9.

${ }^{30}$ Coiffier B, Adeleine P, Viala JJ, et al. Dysmyelopoietic syndromes: a search for prognostic factors in 193 patients. Cancer 1983:52:83-90.

${ }^{31}$ Juneja SK, Imbert M, Sigaux F, Jouault H, Sultan C. Prevalence and distribution of ringed sideroblasts in primary myelodysplastic syndromes. J Clin Pathol 1983;36:566-9.

Requests for reprints to: Professor C Sultan, Central Service of Haematology-Immunology, Henri Mondor Hospital, 94010 Créteil, France. 